\title{
Rhenium-Catalyzed Dehydration of Nonbenzylic and Terpene Alcohols to Olefins
}

\author{
Ties J. Korstanje, Esther F. de Waard, Johann T. B. H. Jastrzebski, and Robertus J. M. Klein Gebbink* \\ Organic Chemistry \& Catalysis, Debye Institute for Nanomaterials Science, Utrecht University, Universiteitsweg 99, 3584 CG \\ Utrecht, The Netherlands
}

ABSTRACT: With the increasing importance of research into biomass as a feedstock for the chemical industry, new methods to reduce the oxygen content of biomass are required. Here, we present our progress in the field of the dehydration reaction, using various rhenium-based catalysts, with rhenium(VII) oxide as the most active catalyst. A wide range of allylic, aliphatic, and homoallylic alcohols have been used as substrates under relatively mild conditions $\left(100-150{ }^{\circ} \mathrm{C}, 0.5 \mathrm{~mol} \%\right.$ catalyst loading, technical toluene, ambient atmosphere) as well as various biobased terpene alcohols. Furthermore, we have applied our protocol to tea tree oil as a proof of concept for the catalytic upgrading of essential oils. The reactivity and selectivity of rhenium(VII) oxide is compared with a classical acid catalyst; sulfuric acid; and solid acid catalysts, such as acid resins, zeolites, and mesoporous materials. It was found that rhenium(VII) oxide surpasses all these catalysts in both activity and selectivity and also shows enduring activity after seven recycling runs.

KEYWORDS: dehydration, catalysis, rhenium, nonbenzylic alcohols, terpene alcohols

\section{INTRODUCTION}

Currently, the majority of the chemical industry is using fossilbased feedstocks. Because these are running out, the search for an alternative resource is of growing importance. A possible alternative resource that could supply the building blocks required by chemical industry in a sustainable fashion is biomass. Biomass can provide sufficient carbon-based material on a yearly basis to supply the current chemical industry with feedstock for production. ${ }^{1,2}$ Biomass, however, is of very different chemical composition from fossil resources. The most important difference is its high oxygen content, which is mostly present in the form of alcohol and ether groups. To obtain building blocks from biomass that are currently used by the chemical industry, this oxygen-to-carbon ratio has to be lowered by either converting or removing the alcohol functional groups. $^{3-5}$ One of the methods to remove alcohol groups is via the dehydration reaction, converting them into olefinic moieties (Scheme 1).

Dehydration reactions are currently performed using strong acid catalysts, such as sulfuric acid or $p$-toluenesulfonic acid, ${ }^{6}$ or solid acids, such as zeolites, ${ }^{7}$ alumina, ${ }^{8}$ or zirconia. ${ }^{8,9}$ The major problems with these methods are their low selectivity and low functional group tolerance as well as their acidic nature, causing reactor corrosion and safety issues. More-selective catalysts for

Scheme 1. Dehydration of Alcohols to Olefins

$$
\overbrace{R^{\prime}}^{\stackrel{\mathrm{OH}}{\text { [cat] }} \longrightarrow \mathrm{R} / \mathrm{R}^{\prime}}+\mathrm{H}_{2} \mathrm{O}
$$

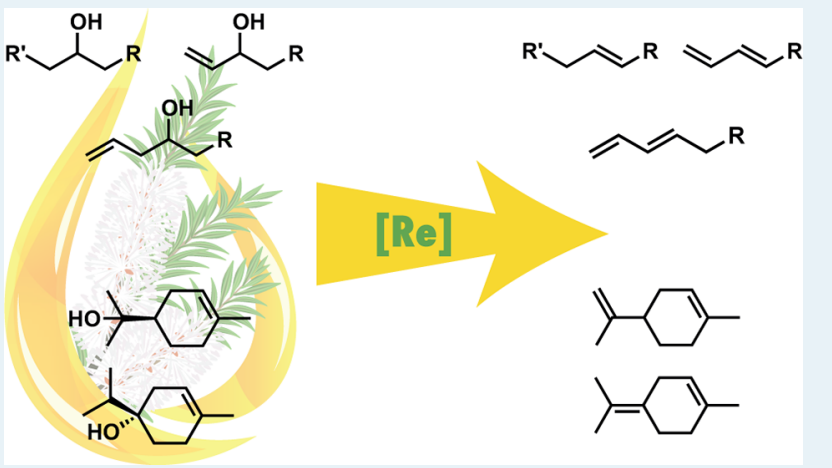

the dehydration reaction that operate under milder conditions are therefore desirable. We envisage that transition metal-based catalysis can be applied to perform this reaction and meet these criteria.

To date, only a few alcohol-to-olefin dehydration reactions catalyzed by transition metal catalysts have been reported. Zincbased catalysts have been reported to be active in the dehydration reaction, ${ }^{10}$ and catalysts based on ruthenium have been shown to be active in the combined dehydration/ hydrogenation of diols. ${ }^{11}$ An interesting nonmetal-catalyzed deoxydehydration reaction was found in the formic acidmediated deoxydehydration of polyols. ${ }^{9}$ One of the very promising catalytic systems for the dehydration reaction is based on high-valence rhenium complexes. Methyltrioxorhenium $\left(\mathrm{CH}_{3} \mathrm{ReO}_{3}, \mathrm{MTO}\right)$ has been found to be active in both the dehydration of alcohols ${ }^{12}$ and the deoxydehydration of diols and polyols. ${ }^{13-15}$ Other rhenium(VII) compounds, such as $\mathrm{NBu}_{4} \mathrm{ReO}_{4}{ }^{14}$ and $\mathrm{Cp} * \mathrm{ReO}_{3}\left(\mathrm{Cp} *=\mathrm{C}_{5} \mathrm{Me}_{5}{ }^{-}\right),{ }^{16}$ have also been found to be active in the deoxydehydration reaction. In addition, the low-valence compounds $\operatorname{Re}_{2}(\mathrm{CO})_{10}$ and BrRe$(\mathrm{CO})_{5}$ have been reported to be active in the deoxydehydration reaction. ${ }^{14}$ Recently, we reported on the reactivity of various rhenium complexes in the dehydration of benzylic alcohols to styrenes and found that high-valence rhenium complexes are more active than low-valence rhenium complexes, with

Received: April 3, 2012

Revised: September 4, 2012

Published: September 7, 2012 
Table 1. $\mathrm{Re}_{2} \mathrm{O}_{7^{-}}$and $\mathrm{H}_{2} \mathrm{SO}_{4}$-Catalyzed Dehydration of Tertiary Allylic, Aliphatic, and Homoallylic Alcohols and Secondary Allylic Alcohols ${ }^{a}$

\begin{tabular}{|c|c|c|c|c|c|c|c|c|}
\hline \multirow[b]{2}{*}{ Entry } & \multirow[b]{2}{*}{ Substrate } & \multirow[b]{2}{*}{ Product } & \multicolumn{3}{|c|}{$\mathrm{Re}_{2} \mathrm{O}_{7}(0.5 \mathrm{~mol} \%)$} & \multicolumn{3}{|c|}{$\mathrm{H}_{2} \mathrm{SO}_{4}(2.5 \mathrm{~mol} \%)$} \\
\hline & & & $\begin{array}{l}\text { Time } \\
(\mathrm{min})\end{array}$ & $\begin{array}{c}\text { Yield } \\
(\%)\end{array}$ & $\begin{array}{l}\text { Initial rate } \\
\left(\mathrm{mmol} \mathrm{h}^{-1}\right)^{\mathrm{b}, \mathrm{c}}\end{array}$ & $\begin{array}{l}\text { Time } \\
(\mathrm{min})\end{array}$ & $\begin{array}{l}\text { Yield } \\
(\%)\end{array}$ & $\begin{array}{l}\text { Initial rate } \\
\left(\mathrm{mmol} \mathrm{h}^{-1}\right)^{\mathrm{b}, \mathrm{c}}\end{array}$ \\
\hline 1 & & & 15 & $75^{\mathrm{b}}$ & 18.5 & 20 & $58^{\mathrm{b}}$ & 9.35 \\
\hline 2 & & & 30 & $56^{\mathrm{d}}$ & 12.6 & 20 & $80^{\mathrm{d}}$ & 10.1 \\
\hline 3 & & & 60 & $84^{\mathrm{b}, \mathrm{e}}$ & 1.15 & 60 & $60^{\mathrm{b}, \mathrm{e}}$ & 6.29 \\
\hline 4 & & & 20 & $96^{\mathrm{d}}$ & 4.44 & 30 & $95^{\mathrm{d}}$ & 4.80 \\
\hline 5 & & & 5 & $40^{\mathrm{b}, \mathrm{f}}$ & 8.95 & 60 & $29^{\mathrm{b}, \mathrm{f}}$ & 1.0 \\
\hline
\end{tabular}

${ }^{a}$ Reaction conditions: $2 \mathrm{mmol}$ of substrate, $0.01 \mathrm{mmol}$ of $\mathrm{Re}_{2} \mathrm{O}_{7}$ or $0.05 \mathrm{mmol}$ of $\mathrm{H}_{2} \mathrm{SO}_{4}, 250 \mu \mathrm{L}$ of pentadecane (IS for GC) or $0.67 \mathrm{mmol}$ of $1,3,5$ trimethoxybenzene (IS for NMR), $10 \mathrm{~mL}$ of toluene, air, magnetic stirring, $100{ }^{\circ} \mathrm{C}$, full conversion, all values averaged over 2 runs. ${ }^{b} \mathrm{Based}$ on GC. ${ }^{c}$ Rate of consumption of starting material in the first 5 min of reaction. ${ }^{d}$ Based on NMR. ${ }^{e}$ Mixture of isomers, quantified after hydrogenation using 10 wt $\%$ Pd on activated carbon. $f_{40 \%}$ conversion.

Table 2. $\mathrm{Re}_{2} \mathrm{O}_{7}$ - and $\mathrm{H}_{2} \mathrm{SO}_{4}$-Catalyzed Dehydration of Primary and Secondary Aliphatic and Homoallylic Alcohols ${ }^{a}$

\begin{tabular}{|c|c|c|c|c|c|c|c|c|}
\hline \multirow[b]{2}{*}{ Entry } & \multirow[b]{2}{*}{ Substrate } & \multirow[b]{2}{*}{ Product } & \multicolumn{3}{|c|}{$\mathrm{Re}_{2} \mathrm{O}_{7}(0.5 \mathrm{~mol} \%)$} & \multicolumn{3}{|c|}{$\mathrm{H}_{2} \mathrm{SO}_{4}(2.5 \mathrm{~mol} \%)$} \\
\hline & & & $\begin{array}{l}\text { Time } \\
\text { (h) }\end{array}$ & $\begin{array}{c}\text { Conversion } \\
(\%)^{\mathrm{b}}\end{array}$ & $\begin{array}{l}\text { Yield } \\
(\%)^{b}\end{array}$ & $\begin{array}{l}\text { Time } \\
\text { (h) }\end{array}$ & $\begin{array}{c}\text { Conversion } \\
(\%)^{\mathrm{b}}\end{array}$ & $\begin{array}{l}\text { Yield } \\
(\%)^{b}\end{array}$ \\
\hline 1 & & heptatrienes & 4.5 & 66 & $33^{c}$ & 24 & 47 & $22^{c}$ \\
\hline 2 & & octadienes & 4 & 77 & $38^{\mathrm{c}}$ & 4 & 32 & $8^{c}$ \\
\hline \multirow{3}{*}{3} & & 1-octene & \multirow{3}{*}{3} & \multirow{3}{*}{81} & 19 & & \multirow{3}{*}{100} & 9 \\
\hline & & $\begin{array}{c}\text { cis-2-octene } \\
\text { trans-2-octene }\end{array}$ & & & $\begin{array}{l}26 \\
29\end{array}$ & 24 & & $\begin{array}{l}33 \\
38\end{array}$ \\
\hline & & trans-3-octene & & & 3 & & & 21 \\
\hline 4 & & 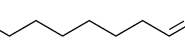 & 24 & 82 & 18 & 24 & 0 & 0 \\
\hline
\end{tabular}

${ }^{a}$ Reaction conditions: $2 \mathrm{mmol}$ of substrate, $0.01 \mathrm{mmol}$ of $\mathrm{Re}_{2} \mathrm{O}_{7}$ or $0.05 \mathrm{mmol}$ of $\mathrm{H}_{2} \mathrm{SO}_{4}, 250 \mu \mathrm{L}$ of pentadecane (IS), $10 \mathrm{~mL}$ of toluene, air (autogenic pressure), mechanical stirring, $150{ }^{\circ} \mathrm{C}$, Parr autoclave, all values averaged over 2 runs. ${ }^{b}$ Based on GC. ${ }^{c}$ Mixture of isomers, quantified after hydrogenation using 10 wt \% Pd on activated carbon.

rhenium(VII) oxide $\left(\mathrm{Re}_{2} \mathrm{O}_{7}\right)$ as the most active catalyst. ${ }^{17}$ With this catalyst, we were able to obtain high yields of styrenes using mild conditions, $100{ }^{\circ} \mathrm{C}$ as reaction temperature, ambient atmosphere, and technical grade toluene as the solvent. Furthermore, $\mathrm{Re}_{2} \mathrm{O}_{7}$ has a higher activity than the benchmark catalyst, sulfuric acid, and displays an increased selectivity to give a higher yield of styrenes.

Here, we report on the extension of the scope of the dehydration reaction to nonbenzylic alcohols and terpene alcohols to the corresponding olefins using rhenium(VII) oxide as the catalyst under mild conditions.

\section{RESULTS}

First, we set out to explore the reactivity of the $\mathrm{Re}_{2} \mathrm{O}_{7}$-based catalytic system to extend the substrate scope beyond benzylic alcohols. A range of allylic, aliphatic, and homoallylic alcohols was tested in the dehydration reaction and compared with the benchmark dehydration catalyst, sulfuric acid $\left(\mathrm{H}_{2} \mathrm{SO}_{4}\right)$.

These reactions were performed using technical grade toluene as the solvent under ambient conditions and at a mild reaction temperature of $100{ }^{\circ} \mathrm{C}$, using $0.5 \mathrm{~mol} \% \mathrm{Re}_{2} \mathrm{O}_{7}$ or $2.5 \mathrm{~mol} \% \mathrm{H}_{2} \mathrm{SO}_{4}$. The results are depicted in Table 1. 2Cyclohexen-1-ol is smoothly dehydrated to cyclohexa-1,3-diene in $75 \%$ yield with $\mathrm{Re}_{2} \mathrm{O}_{7}$, and $\mathrm{H}_{2} \mathrm{SO}_{4}$ showed half of the activity of $\mathrm{Re}_{2} \mathrm{O}_{7}$ and a lower diene yield (entry 1). Substrate conversion is complete, with both catalysts and additional reaction products not mentioned in the table likely being higher-boiling oligomers or Diels-Alder products that do not elute from the GC column. In the dehydration of the tertiary allylic alcohol 1-vinylcyclohexanol, similar catalytic activities were observed, although in this case, $\mathrm{H}_{2} \mathrm{SO}_{4}$ gives the higher product yield (entry 2 ). In the case of the tertiary homoallylic alcohol 3-methyl-5-hexen-3-ol, the result is the opposite, with $\mathrm{H}_{2} \mathrm{SO}_{4}$ being the more active catalyst but $\mathrm{Re}_{2} \mathrm{O}_{7}$ giving the higher product yield (entry 3 ). Use of the tertiary aliphatic alcohol 3-ethyl-3-pentanol gave similar activities for both catalysts and also a similar yield (95\%) of the corresponding olefin (entry 4). For these tertiary and cyclic secondary allylic alcohols, conversions were complete in only 15 to $60 \mathrm{~min}$ of reaction time. When applying the same conditions to the linear 
Table 3. Rhenium-Catalyzed Dehydration of $\alpha$-Terpineol to Limonene and Terpinolene ${ }^{a}$

\begin{tabular}{|c|c|c|c|c|c|c|c|}
\hline \multirow[b]{2}{*}{ entry } & \multirow[b]{2}{*}{ catalyst } & \multirow[b]{2}{*}{ time $(\mathrm{h})$} & \multirow[b]{2}{*}{ conversion $(\%)^{b}$} & \multicolumn{3}{|c|}{ yield $(\%)^{b}$} & \multirow[b]{2}{*}{ initial rate $\left(\mathrm{mmol} \mathrm{h}^{-1}\right)^{b, d}$} \\
\hline & & & & limonene & terpinolene & others $^{c}$ & \\
\hline 1 & & 24 & 0 & & & & \\
\hline 2 & $\operatorname{Re}(0)$ & 24 & 42 & 28 & 12 & 3 & 0.105 \\
\hline 3 & $\operatorname{Re}_{2}(\mathrm{CO})_{10}{ }^{e}$ & 24 & 89 & 62 & 18 & 3 & 0.099 \\
\hline 4 & $\operatorname{Re}(\mathrm{CO})_{5} \mathrm{Cl}$ & 1.5 & $>99$ & 50 & 35 & 9 & 1.9 \\
\hline 5 & $\mathrm{ReIO}_{2}\left(\mathrm{PPh}_{3}\right)_{2}$ & 1.5 & $>99$ & 61 & 28 & 5 & 2.0 \\
\hline 6 & $\mathrm{ReOCl}_{3}\left(\mathrm{PPh}_{3}\right)_{2}$ & 3 & $>99$ & 61 & 31 & 2 & 0.84 \\
\hline 7 & $\mathrm{CH}_{3} \mathrm{ReO}_{3}$ & 4 & $>99$ & 66 & 24 & 3 & $0.48^{f}$ \\
\hline 8 & $\mathrm{HReO}_{4}(\mathrm{aq})$ & 1 & $>99$ & 57 & 32 & 6 & 4.7 \\
\hline 9 & $\mathrm{Re}_{2} \mathrm{O}_{7}{ }^{e}$ & 0.75 & $>99$ & 65 & 35 & & 6.3 \\
\hline 10 & $\mathrm{KReO}_{4}$ & 24 & 0 & & & & \\
\hline 11 & $\mathrm{NBu}_{4} \mathrm{ReO}_{4}$ & 24 & 0 & & & & \\
\hline 12 & $\mathrm{NH}_{4} \mathrm{ReO}_{4}$ & 24 & 12 & 5 & 2 & & $<0.1$ \\
\hline
\end{tabular}

${ }^{a}$ Reaction conditions: $2 \mathrm{mmol}$ of $\alpha$-terpineol, $0.02 \mathrm{mmol}$ of catalyst, $10 \mathrm{~mL}$ of toluene, air, magnetic stirring, $100{ }^{\circ} \mathrm{C}$, all values averaged over 2 runs. ${ }^{b}$ Based on GC. ${ }^{c}$ Other compounds detected: $\alpha$-terpinene, $\gamma$-terpinene, and $p$-cymene. ${ }^{d}$ Rate of consumption of starting material in the first 15 min (entries 8 and 9), $30 \mathrm{~min}$ (entries 4 and 5), $60 \mathrm{~min}$ (entry 6), $90 \mathrm{~min}$ (entry 7), $4 \mathrm{~h}$ (entries 2 and 3), or $24 \mathrm{~h}$ (entry 12 ) of reaction. ${ }^{e} 0.01 \mathrm{mmol}$ of

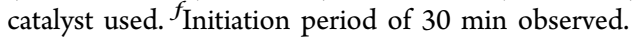

Table 4. Effect of $\operatorname{Re}_{2} \mathrm{O}_{7}$ Loading on the $\alpha$-Terpineol Dehydration Reaction ${ }^{a}$

\begin{tabular}{|c|c|c|c|c|c|c|c|}
\hline \multirow[b]{2}{*}{ entry } & \multirow[b]{2}{*}{ loading (mol \%) } & \multirow[b]{2}{*}{ time $(\mathrm{h})$} & \multirow[b]{2}{*}{ conversion $(\%)^{b}$} & \multicolumn{3}{|c|}{ yield $(\%)^{b}$} & \multirow[b]{2}{*}{ initial rate $\left(\mathrm{mmol} \mathrm{h}^{-1}\right)^{b, d}$} \\
\hline & & & & limonene & terpinolene & others $^{c}$ & \\
\hline 1 & 0.5 & 0.75 & $>99$ & 65 & 35 & & 6.3 \\
\hline 2 & 0.1 & 5 & $>99$ & 52 & 33 & 8 & 2.3 \\
\hline 3 & 0.05 & 4 & $>99$ & 60 & 29 & & 1.1 \\
\hline 4 & 0.02 & 24 & 89 & 59 & 29 & 1 & 0.35 \\
\hline
\end{tabular}

${ }^{a}$ Reaction conditions: $2-50 \mathrm{mmol}$ of $\alpha$-terpineol, $0.01 \mathrm{mmol}$ of $\mathrm{Re}_{2} \mathrm{O}_{7}, 10-250 \mathrm{~mL}$ of toluene, air, magnetic stirring, $100{ }^{\circ} \mathrm{C}$, all values averaged over 2 runs. ${ }^{b}$ Based on GC. ${ }^{c}$ Other compounds detected: $\alpha$-terpinene, $\gamma$-terpinene, and $p$-cymene. ${ }^{d}$ Rate of consumption of starting material in the first $15 \mathrm{~min}$ (entries 1 and 2), $30 \mathrm{~min}$ (entry 3), or $120 \mathrm{~min}$ (entry 4) of reaction.

secondary allylic alcohol 1-octen-3-ol, complete conversion was not obtained, and no dehydration products were observed; instead, a 1,3-transposition of the alcohol occurred (entry 5). Within 5 min, the reaction with $\operatorname{Re}_{2} \mathrm{O}_{7}$ reached equilibrium at a 60:40 ratio of the starting compound and 2-octen-1-ol. This is in accordance with an earlier report that gave a similar equilibrium ratio for this 1,3-transposition reaction, catalyzed by MTO. ${ }^{18}$ We also found that $\mathrm{H}_{2} \mathrm{SO}_{4}$ catalyzes this transposition reaction, although not as efficiently as $\mathrm{Re}_{2} \mathrm{O}_{7}$.

With secondary aliphatic or homoallylic alcohols, no reaction was observed with either catalyst under these reaction conditions. Raising the reaction temperature to $150{ }^{\circ} \mathrm{C}$ in an autoclave did allow for the dehydration of these alcohols (Table 2). Using 1,6-heptan-4-ol as the substrate gave a mixture of different heptatrienes. The total yield in heptatriene was determined after hydrogenation to heptane: $35 \%$ at $66 \%$ conversion for $\mathrm{Re}_{2} \mathrm{O}_{7}$ after $4 \mathrm{~h}$ and $22 \%$ at $47 \%$ conversion for $\mathrm{H}_{2} \mathrm{SO}_{4}$ after $24 \mathrm{~h}$ (entry 1). Similar results were obtained with 1-octen-4-ol as the substrate and $\mathrm{Re}_{2} \mathrm{O}_{7}$ as catalyst, yielding $38 \%$ of octatriene at $77 \%$ conversion of the alcohol, whereas with $\mathrm{H}_{2} \mathrm{SO}_{4}$, only $8 \%$ of dehydration products was obtained at $32 \%$ conversion (entry 2 ).

The dehydration of 2-octanol is of particular interest because the corresponding dehydration product, 1-octene, is widely used as a comonomer for polyolefins, such as linear low-density polyethylene (LLDPE). ${ }^{19} \mathrm{Re}_{2} \mathrm{O}_{7}$ gave a good yield of octenes after $4 \mathrm{~h}$ (77\% yield, $81 \%$ conversion), forming a mixture of primarily 1-, cis-2-, and trans-2-octene in a 0.75:1:1.12 ratio as determined by GC (entry 3). In the case of $\mathrm{H}_{2} \mathrm{SO}_{4}$, a similar yield in octenes of $82 \%$ was obtained, but after longer reaction time $(24 \mathrm{~h})$ and at full conversion. However, with $\mathrm{H}_{2} \mathrm{SO}_{4}$, much more internal alkenes, including 3-octenes, and only minor amounts of 1-octene were formed. Attempts to dehydrate 1octanol failed with both catalysts; no reaction was observed with $\mathrm{H}_{2} \mathrm{SO}_{4}$, while with $\mathrm{Re}_{2} \mathrm{O}_{7}$, oxidation to octanal was observed together with the formation of trace amounts of octanoic acid and octyl octanoate (entry 4 ).

When the $\mathrm{Re}_{2} \mathrm{O}_{7}$-catalyzed reaction with 1-octanol, yielding octanal, was carried out in the absence of air, no conversion was observed, indicating that oxygen from the air serves as the oxidant in this reaction. Oxidative transformations of alcohols to aldehydes and acids using oxygen as oxidant and (supported) rhenium oxides as catalyst are well-known in the literature, although usually higher temperatures are needed. ${ }^{20}$

Having tested the activity of $\operatorname{Re}_{2} \mathrm{O}_{7}$ in the dehydration of some typical alcohol structural fragments, we turned our attention to the dehydration of terpene alcohols to terpenes. We first performed a catalyst screening with a series of commercially available rhenium-based compounds in the dehydration of the terpene alcohol $\alpha$-terpineol using the same reaction conditions, with technical toluene as the solvent under ambient atmosphere and $100{ }^{\circ} \mathrm{C}$ as the reaction temperature (Table 3). Under these conditions, the major products in this reaction are limonene and terpinolene, with 
Table 5. $\mathrm{Re}_{2} \mathrm{O}_{7^{-}}$and $\mathrm{H}_{2} \mathrm{SO}_{4}$-catalyzed dehydration of terpene alcohols at $100{ }^{\circ} \mathrm{C}^{a}$

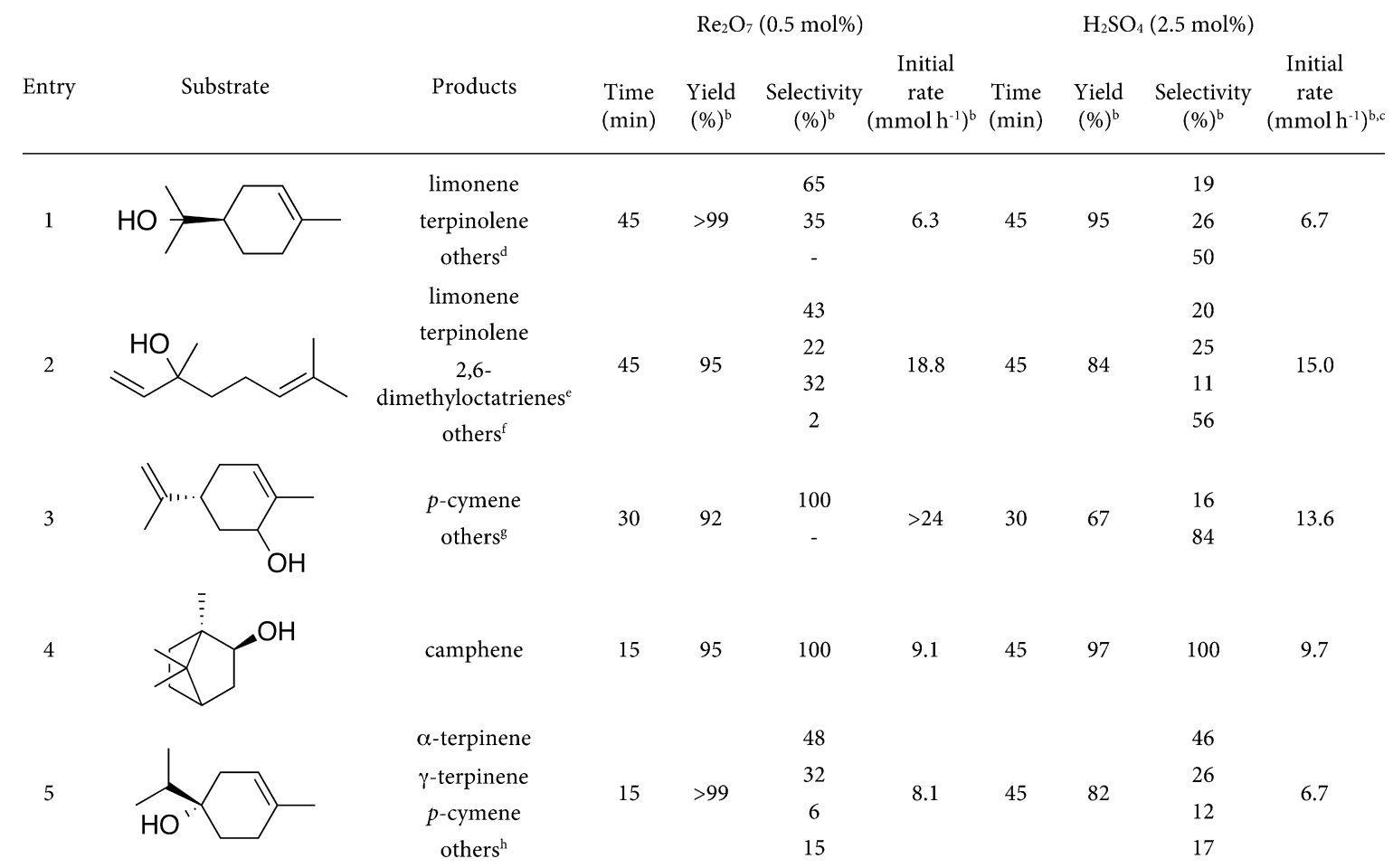

${ }^{a}$ Reaction conditions: $2 \mathrm{mmol}$ of substrate, $0.01 \mathrm{mmol}$ of $\mathrm{Re}_{2} \mathrm{O}_{7}$ or $0.05 \mathrm{mmol}$ of $\mathrm{H}_{2} \mathrm{SO}_{4}, 250 \mu \mathrm{L}$ of pentadecane (IS), $10 \mathrm{~mL}$ of toluene, air, magnetic stirring, $100{ }^{\circ} \mathrm{C}$, full conversion, all values averaged over 2 runs. ${ }^{b}$ Based on GC. ${ }^{c}$ Rate of consumption of starting material in the first 5 min of reaction. ${ }^{d} \alpha$-Terpinene, $\gamma$-terpinene, and $p$-cymene. ${ }^{e}$ Mixture of isomers, quantified after hydrogenation using $10 \mathrm{wt} \% \mathrm{Pd}$ on activated carbon. ${ }^{f} p$ Cymene and $\gamma$-terpinene. ${ }^{g} p$-Mentha-2,5,8-triene, $p, \alpha$-dimethylstyrene, and an unidentified product. ${ }^{h}$ Terpinolene and isoterpinolene.

minor formation of $\alpha$-terpinene, $\gamma$-terpinene, and para-cymene. Most of the tested rhenium-based catalysts showed significant activity in this dehydration reaction. The more active catalysts (entries 4-9) are able to dehydrate $\alpha$-terpineol with complete conversion within only $4 \mathrm{~h}$ of reaction time. The most active catalyst was found to be $\mathrm{Re}_{2} \mathrm{O}_{7}$ (entry 9), which is able to reach full conversion within only $45 \mathrm{~min}$.

In addition, perrhenic acid $\left(\mathrm{HReO}_{4}\right.$, entry 8$), \mathrm{Re}(\mathrm{CO})_{5} \mathrm{Cl}$, and $\mathrm{ReIO}_{2}\left(\mathrm{PPh}_{3}\right)_{2}$ (entries 4 and 5 ) are very active catalysts, requiring 1 and $1.5 \mathrm{~h}$, respectively, to completely convert $\alpha$ terpineol to the corresponding terpenes. Concerning selectivity, the best-performing catalyst is again $\mathrm{Re}_{2} \mathrm{O}_{7}$. It was the only catalyst that showed only trace formation of side products in this reaction; the other tested rhenium-based catalysts showed 2-9\% side product formation.

Next, we tested the effect of lowering the amount of $\mathrm{Re}_{2} \mathrm{O}_{7}$ on the $\alpha$-terpineol dehydration reaction (Table 4). Using down to $0.05 \mathrm{~mol} \%$ of $\mathrm{Re}_{2} \mathrm{O}_{7}$ as catalyst (entries 1-3), full conversion was obtained within several hours, but upon using $0.02 \mathrm{~mol} \% \mathrm{Re}_{2} \mathrm{O}_{7}$, full conversion was not obtained within $24 \mathrm{~h}$ (entry 4). The initial rate of the reaction also dropped as a consequence of the lowering of the catalyst amount from 6.3 to $0.35 \mathrm{mmol} \mathrm{h}^{-1}$. Because of these characteristics, we decided to continue using $0.5 \mathrm{~mol} \%$ of catalyst as the optimal catalyst loading.

After this catalyst screening and loading optimization, $\mathrm{Re}_{2} \mathrm{O}_{7}$ at $0.5 \mathrm{~mol} \%$, as both the most active and selective catalyst, was tested in the dehydration of a broad range of terpene alcohols and compared with sulfuric acid $\left(\mathrm{H}_{2} \mathrm{SO}_{4}\right)$ at $2.5 \mathrm{~mol} \%$ as a benchmark catalyst (Table 5). In the dehydration of $\alpha$-terpineol (entry 1), $\mathrm{H}_{2} \mathrm{SO}_{4}$ produces a mixture of five different compounds, with no clear preference for any of the products and with the highest selectivity for terpinolene at $26 \%$, and $\mathrm{Re}_{2} \mathrm{O}_{7}$ produced only limonene and terpinolene in a 65:35 ratio. This remarkable selectivity difference was further investigated by testing the reactivity under the reaction conditions of both limonene and terpinolene, which can be considered the primary products of the dehydration of $\alpha$ terpineol. Using $\mathrm{Re}_{2} \mathrm{O}_{7}$, very little isomerization of both compounds ( $6 \%$ and $8 \%$ conversion, respectively, after 45 min and an initial rate of 0.16 and $0.10 \mathrm{mmol} \mathrm{h}^{-1}$ ) is observed, whereas with $\mathrm{H}_{2} \mathrm{SO}_{4}$, rapid reaction toward $\alpha$-terpinene, $p$ cymene, and $\gamma$-terpinene is observed (33\% and $22 \%$ conversion, respectively, after $45 \mathrm{~min}$ and an initial rate of 1.0 and 0.58 $\mathrm{mmol} \mathrm{h}^{-1}$ ). In the dehydration of $(-)$-linalool (entry 2 ), similar results were obtained, with $\operatorname{Re}_{2} \mathrm{O}_{7}$ showing somewhat better activity, but a much better selectivity. With $\operatorname{Re}_{2} \mathrm{O}_{7}$, three products are formed in significant amounts, with limonene as the major product in $41 \%$ selectivity, and with $\mathrm{H}_{2} \mathrm{SO}_{4}$, six products are formed with terpinolene as the major product in only $25 \%$ selectivity.

The formation of limonene and terpinolene from linalool is a known reaction and has been proposed to proceed via an allylic carbocation intermediate, which shifts from the 3- to the 1position, followed by ring closure and deprotonation. ${ }^{19}$ In the case of carveol, the difference in both selectivity and activity is even larger: with $\mathrm{Re}_{2} \mathrm{O}_{7}$, para-cymene is formed as the only product in a very good yield of $92 \%$, whereas with $\mathrm{H}_{2} \mathrm{SO}_{4}$, multiple compounds are formed, and only $16 \%$ selectivity for para-cymene is obtained (entry 3 ). On the other hand, when using isoborneol as substrate, not much difference is observed between the two catalysts, both forming exclusively camphene via the well-known Wagner-Meerwein rearrangement (entry $4) .{ }^{21}$ Also in the case of (-)-terpinen-4-ol, little difference is 
Table 6. $\mathrm{Re}_{2} \mathrm{O}_{7}$ - and $\mathrm{H}_{2} \mathrm{SO}_{4}$-Catalyzed Dehydration of Terpene Alcohols at $150{ }^{\circ} \mathrm{C}^{a}$

\begin{tabular}{|c|c|c|c|c|c|c|c|c|c|c|}
\hline \multirow[b]{2}{*}{ Entry } & \multirow[b]{2}{*}{ Substrate } & \multirow[b]{2}{*}{ Product } & \multicolumn{4}{|c|}{$\operatorname{Re}_{2} \mathrm{O}_{7}(0.5 \mathrm{~mol} \%)$} & \multicolumn{4}{|c|}{$\mathrm{H}_{2} \mathrm{SO}_{4}(2.5 \mathrm{~mol} \%)$} \\
\hline & & & $\begin{array}{l}\text { Time } \\
\text { (h) }\end{array}$ & $\begin{array}{c}\text { Conversion } \\
(\%)^{\mathrm{b}}\end{array}$ & $\begin{array}{l}\text { Yield } \\
(\%)^{\mathrm{b}}\end{array}$ & $\begin{array}{c}\text { Selectivity } \\
(\%)^{\mathrm{b}}\end{array}$ & $\begin{array}{l}\text { Time } \\
\text { (h) }\end{array}$ & $\begin{array}{c}\text { Conversion } \\
(\%)^{\mathrm{b}}\end{array}$ & $\begin{array}{l}\text { Yield } \\
(\%)^{\mathrm{b}}\end{array}$ & $\begin{array}{l}\text { Selectivity } \\
\text { (\%) }\end{array}$ \\
\hline 1 & & $\begin{array}{l}\text { camphene } \\
\text { camphor }\end{array}$ & 48 & 51 & 51 & $\begin{array}{l}51 \\
49\end{array}$ & 48 & 56 & 42 & $\begin{array}{c}100 \\
-\end{array}$ \\
\hline & & $p$-menth-1-ene ${ }^{c}$ & & & & 11 & & & & - \\
\hline 2 & & $\begin{array}{l}p \text {-menth-2-ene } e^{c} \\
p \text {-menth-3-ene }\end{array}$ & 24 & $>99$ & $>99$ & $\begin{array}{c}82 \\
7\end{array}$ & 48 & 12 & 12 & $\begin{array}{c}93 \\
7\end{array}$ \\
\hline 3 & & $\begin{array}{l}p \text {-menth-1-ene } e^{c} \\
p \text {-menth-2-ene } \\
p \text {-menth-3-ene }\end{array}$ & 24 & $>99$ & $>99$ & $\begin{array}{c}6 \\
85 \\
9\end{array}$ & 48 & 57 & 54 & $\begin{array}{c}1 \\
90 \\
9\end{array}$ \\
\hline 4 & & $\begin{array}{c}\alpha \text {-terpinene } \\
\text { isoterpinolene } \\
\text { others }^{\mathrm{d}}\end{array}$ & 24 & 79 & 16 & $\begin{array}{l}32 \\
42 \\
26\end{array}$ & 24 & 30 & 4 & $-e^{e}$ \\
\hline
\end{tabular}

${ }^{a}$ Reaction conditions: $2 \mathrm{mmol}$ of substrate, $0.01 \mathrm{mmol}$ of $\mathrm{Re}_{2} \mathrm{O}_{7}$ or $0.05 \mathrm{mmol}$ of $\mathrm{H}_{2} \mathrm{SO}_{4}, 250 \mu \mathrm{L}$ of pentadecane (IS), $10 \mathrm{~mL}$ of toluene, air (autogenic pressure), magnetic stirring, $150{ }^{\circ} \mathrm{C}$, Ace pressure tube, all values averaged over 2 runs. ${ }^{b}$ Based on GC. ${ }^{c} p$-Menth-1-ene, 4 -isopropyl-1methylcyclohexene; $p$-menth-2-ene, 3-isopropyl-6-methylcyclohexene; $p$-menth-3-ene, 1-isopropyl-4-methylcyclohexene. ${ }^{d}$ Pulegol, $\gamma$-terpinene, and $p$-cymene. ${ }^{e}$ Trace amounts of $\alpha$-terpinene and $p$-cymene together with pulegol.

observed in activity and selectivity, although a higher total yield is obtained in a shorter time when using $\operatorname{Re}_{2} \mathrm{O}_{7}$ as the catalyst (entry 5).

All terpene alcohols mentioned in Table 5 were dehydrated at a reaction temperature of $100{ }^{\circ} \mathrm{C}$. Interestingly, the reaction of (-)-borneol, the stereoisomer of isoborneol, did not proceed with either catalyst at this temperature. When the reaction temperature was raised to $150{ }^{\circ} \mathrm{C}$, however, both $\mathrm{Re}_{2} \mathrm{O}_{7}$ and $\mathrm{H}_{2} \mathrm{SO}_{4}$ convert borneol to camphene in 51 and $56 \%$ conversion, respectively, although in the case of $\operatorname{Re}_{2} \mathrm{O}_{7}$, oxidation to camphor was also observed (Table 6, entry 1 ).

In addition, the secondary aliphatic alcohols menthol and isomenthol (entries 2 and 3) did not react at $100{ }^{\circ} \mathrm{C}$, but were converted smoothly at $150{ }^{\circ} \mathrm{C}$ to the corresponding menthenes with $\mathrm{Re}_{2} \mathrm{O}_{7}$, whereas $\mathrm{H}_{2} \mathrm{SO}_{4}$ showed moderate to poor conversions, even after $48 \mathrm{~h}$. The secondary homoallylic alcohol isopulegol (entry 4) gave a poor mass balance with both catalysts at $150{ }^{\circ} \mathrm{C}$, indicating the formation of side products with higher boiling points.

Because we demonstrated the use of $\mathrm{Re}_{2} \mathrm{O}_{7}$ as a potent catalyst for the dehydration of various terpene alcohols to terpenes, we decided to apply this procedure to tea tree oil as a proof of principle for the catalytic upgrading of essential oils. Tea tree oil is the essential oil obtained by pressing the leaves of the Melaleuca alternifolia and consists mostly of terpinen-4-ol (48\%, Table 7) and $\alpha$ - and $\gamma$-terpinene (10\% and 23\%, respectively), with minor amounts of $\alpha$-terpineol (7\%) and some other terpenes. We applied our $\operatorname{Re}_{2} \mathrm{O}_{7}$-catalyzed dehydration protocol on this essential oil and were able to upgrade the oil within $30 \mathrm{~min}$, converting all terpene alcohols and yielding $35 \%$ and $39 \%$ of $\alpha$ - and $\gamma$-terpinene, respectively, as the predominant compounds. Because the dehydration products are already present in the untreated oil, the upgraded oil contains fewer components, thus increasing both yield and ease of separation of the terpenes. With $\mathrm{H}_{2} \mathrm{SO}_{4}$, a similar
Table 7. $\mathrm{Re}_{2} \mathrm{O}_{7^{-}}$and $\mathrm{H}_{2} \mathrm{SO}_{4^{-}}$Catalyzed Dehydrative Upgrading of Tea Tree Oil ${ }^{a}$

\begin{tabular}{lrcc}
\multicolumn{1}{c}{ compound } & $\begin{array}{c}\text { tea tree } \\
\text { oil }\end{array}$ & $\begin{array}{c}\mathrm{Re}_{2} \mathrm{O}_{7} \\
(0.5 \mathrm{~mol} \%, 30 \mathrm{~min})\end{array}$ & $\begin{array}{c}\mathrm{H}_{2} \mathrm{SO}_{4} \\
(2.5 \mathrm{~mol} \mathrm{\% ,3} \mathrm{h})\end{array}$ \\
terpinen-4-ol & 48 & 0 & 0 \\
$\alpha$-terpineol & 7 & 0 & 0 \\
$\alpha$-terpinene & 10 & 35 & 34 \\
$\gamma$-terpinene & 23 & 39 & 36 \\
limonene & 1 & 5 & 4 \\
terpinolene & 4 & 9 & 13 \\
isoterpinolene & 0 & 2 & 0 \\
$p$-cymene & 7 & 11 & 13 \\
mass balance & & 92 & 86
\end{tabular}

${ }^{a}$ Reaction conditions: $617 \mu \mathrm{L}$ of tea tree oil, $0.01 \mathrm{mmol}$ of $\mathrm{Re}_{2} \mathrm{O}_{7}$ or $0.05 \mathrm{mmol}$ of $\mathrm{H}_{2} \mathrm{SO}_{4}, 250 \mu \mathrm{L}$ of pentadecane (IS), $10 \mathrm{~mL}$ of toluene, $100{ }^{\circ} \mathrm{C}$, air, magnetic stirring, $30^{\prime}$ or $3 \mathrm{~h}$, values are selectivities based on GC and averaged over 2 runs.

mixture was obtained after the reaction, but it took $3 \mathrm{~h}$ to completely convert all the terpene alcohols to terpenes.

During all experiments performed with $\mathrm{Re}_{2} \mathrm{O}_{7}$ as the catalyst, it was observed that $\mathrm{Re}_{2} \mathrm{O}_{7}$ does not (completely) dissolve in the reaction medium and is seemingly acting as a heterogeneous catalyst. We therefore have also compared $\mathrm{Re}_{2} \mathrm{O}_{7}$ with various commonly used solid acid catalysts. In Table 8 , the results of the dehydration of $\alpha$-terpineol using various commonly used solid acid catalysts are given, again using technical toluene as the solvent under ambient atmosphere and $100{ }^{\circ} \mathrm{C}$ as the reaction temperature for all catalysts. $\gamma$-Alumina (entry 3 ) showed no reactivity in this reaction, and also the Brønsted acidic resins Amberlite IR120 and Dowex 50WX8 (entries 4 and 5), both styrene divinylbenzene polymers functionalized with sulfonic acid groups, showed no or very little reactivity in this reaction under the given reaction conditions. Montmorillonite K10 (entry 6), a Brønsted acidic clay, showed reasonable activity in this reaction, although the 
Table 8. Dehydration of $\alpha$-Terpineol Using Various Acid Catalysts ${ }^{a}$

\begin{tabular}{|c|c|c|c|c|c|c|c|c|}
\hline \multirow[b]{2}{*}{ entry } & \multirow[b]{2}{*}{ catalyst } & \multirow[b]{2}{*}{ conversion $(\%)^{b}$} & \multicolumn{5}{|c|}{ yield $(\%)^{b}$} & \multirow[b]{2}{*}{ initial rate $\left(\mathrm{mmol} \mathrm{h}^{-1}\right)^{b, c}$} \\
\hline & & & limonene & terpinolene & $\alpha$-terpinene & p-cymene & other & \\
\hline 1 & $\mathrm{Re}_{2} \mathrm{O}_{7}{ }^{d}$ & $>99$ & 65 & 35 & & & & 6.3 \\
\hline 2 & $\mathrm{H}_{2} \mathrm{SO}_{4}^{d, e}$ & $>99$ & 24 & 24 & 24 & 13 & 11 & 6.7 \\
\hline 3 & $\gamma-\mathrm{Al}_{2} \mathrm{O}_{3}$ & 0 & & & & & & \\
\hline 4 & Amberlite IR 120 & 5 & 1 & 1 & & & & $<0.01$ \\
\hline 5 & Dowex 50WX8 & 0 & & & & & & \\
\hline 6 & Montmorillonite $\mathrm{K} 10$ & 86 & 14 & 18 & 9 & 14 & 6 & 1.2 \\
\hline 7 & H-ZSM-5 & 12 & 3 & 3 & & & & 0.01 \\
\hline 8 & H-Beta & 59 & 22 & 12 & 3 & 8 & 4 & 0.49 \\
\hline 9 & $\mathrm{H}-\mathrm{Y}$ & 69 & 18 & 12 & 2 & 15 & 5 & 1.8 \\
\hline 10 & Al-MCM-41 & 51 & 16 & 15 & 3 & 6 & 6 & 0.05 \\
\hline
\end{tabular}

${ }^{a}$ Reaction conditions: $2 \mathrm{mmol}$ of $\alpha$-terpineol, $4.8 \mathrm{mg}$ of catalyst, $10 \mathrm{~mL}$ of toluene, $100{ }^{\circ} \mathrm{C}$, air, magnetic stirring, $24 \mathrm{~h}$, all values averaged over 2 runs. ${ }^{b}$ Based on GC. ${ }^{c}$ Rate of consumption of starting material in the first $15 \mathrm{~min}$ (entries 1,2 and 6 ) or 30 min (entries 8 and 9 ) of reaction. ${ }^{d} 30$ min reaction time. ${ }^{e} 0.05 \mathrm{mmol}$ catalyst used.

selectivity was roughly comparable to that of sulfuric acid and, thus, much lower than $\operatorname{Re}_{2} \mathrm{O}_{7}$.

Next, three different zeolites were tested, ranging from medium- to large-pore-size zeolites. ZSM-5 showed a low activity under these reaction conditions (entry 7), whereas zeolites Beta and Y showed much higher activity, with the latter being the more active (entries 8 and 9). In addition, the mesoporous aluminosilicate Al-MCM-41 showed activity in this reaction (entry 10). All these solid catalysts showed similar selectivities, giving a mixture of five different compounds. $\mathrm{Re}_{2} \mathrm{O}_{7}$ is the one exception, showing a high reaction rate in combination with the formation of only two reaction products in quantitative yield.

Another important characteristic of a solid catalyst is its recycling behavior. Recycling tests for $\mathrm{Re}_{2} \mathrm{O}_{7}$ were performed on the dehydration of $\alpha$-terpineol. Recycling was carried out by centrifugation of the reaction mixture after the catalytic run and subsequent decantation of the solution, followed by addition of a new substrate solution. Seven subsequent runs were carried out in this manner, and both the product yield after $45 \mathrm{~min}$ and the initial reaction rate were recorded (Figure 1). It was found that full conversion was reached after $45 \mathrm{~min}$ during three consecutive runs, but that activity was gradually lost during the seven runs performed. Despite this activity loss, $\mathrm{Re}_{2} \mathrm{O}_{7}$ still showed an activity of $1.1 \mathrm{mmol} \mathrm{h}^{-1}$ in the seventh run, which is comparable to other solid catalysts in their first run, as described above. The selectivity of $\operatorname{Re}_{2} \mathrm{O}_{7}$ remained unchanged

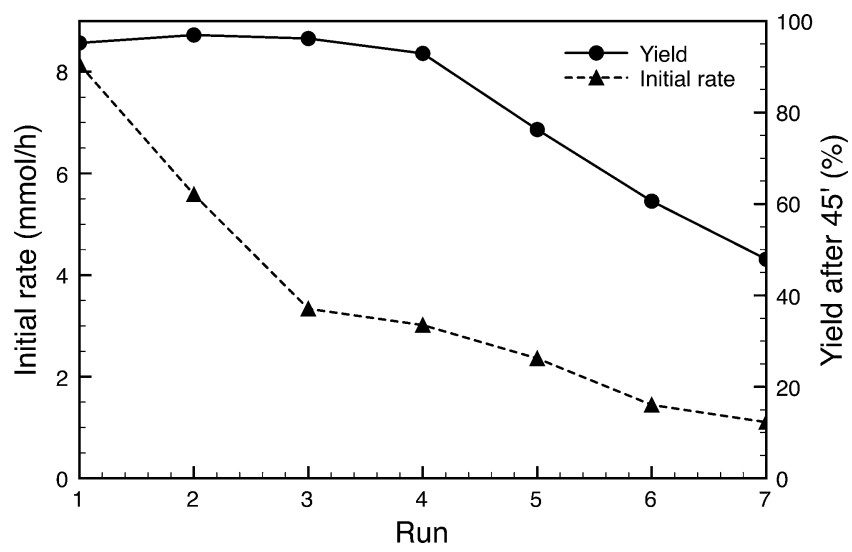

Figure 1. Recycling characteristics of the $\mathrm{Re}_{2} \mathrm{O}_{7}$-catalyzed dehydration of $\alpha$-terpineol. during all runs, with limonene and terpinolene as the major products and only trace formation of other products observed.

One of the factors involved in the recyclability of $\mathrm{Re}_{2} \mathrm{O}_{7}$ is its (partial) solubility in the reaction medium. This factor was monitored by filtration over Celite of a reaction mixture after a catalytic run and subsequent addition of a new substrate solution. The initial rate in the filtrate was compared with a run that was not filtered. Although the observed initial rate in the filtrate was much lower than that of the nonfiltered reaction mixture ( 1.4 versus $5.2 \mathrm{mmol} \mathrm{h}^{-1}$ respectively), the activity that was found for the filtrate was considerable. This also indicates that both dissolved (homogeneous) and solid (heterogeneous) $\mathrm{Re}_{2} \mathrm{O}_{7}$ exhibit catalytic behavior.

\section{DISCUSSION}

Rhenium-Based Catalyst Activity. In the dehydration of benzylic alcohols with rhenium-based catalysts, we previously described a trend of increasing reactivity (based on the initial rate of reaction) with increasing oxidation state of the rhenium metal. ${ }^{17}$ The same trend in reactivity was observed in the catalyst screening for the dehydration of $\alpha$-terpineol, with $\operatorname{Re}$ metal and $\operatorname{Re}_{2}(\mathrm{CO})_{10}$ showing low activity, the $\operatorname{Re}(\mathrm{V})$ species showing good conversion at intermediate activity, and $\mathrm{Re}_{2} \mathrm{O}_{7}$ and $\mathrm{HReO}_{4}$ being the best performing catalysts in terms of both conversion and activity. The only catalyst that falls outside of this trend is $\operatorname{Re}(\mathrm{CO})_{5} \mathrm{Cl}$, which shows activity similar to the $\operatorname{Re}(\mathrm{V})$ species. Also remarkable is the relatively low activity of MTO in comparison with the other catalysts tested in this study and also in comparison with previously obtained results. With this catalyst, we observed an initiation period of $30 \mathrm{~min}$, indicating the formation of an active species other than MTO itself. Further research would be required to determine the nature of this species. Another interesting observation is the very low or even complete lack of activity of the perrhenate salts.

One of the factors that could be considered to explain the observed trends in reactivity for these rhenium-based complexes is their Lewis acidic strength. A higher oxidation state implies a higher Lewis acidic strength, which would enhance binding to the electron-rich alcohol group, thereby weakening the $\mathrm{C}-\mathrm{O}$ bond and activating the substrate for dehydration, thus giving higher activity. The lack of reactivity of the perrhenate salts can also be explained in terms of Lewis acidic strength: because these perrhenates are negatively charged, they are Lewis bases and will therefore be reluctant 
to bind with the electron-rich alcohol group. The ligands attached to the rhenium center exert an additional influence on the Lewis acidic strength of the complexes. Oxo and halide ligands are both $\sigma$ and $\pi$ electron donors, which lowers the Lewis acidic strength of the rhenium center, whereas carbonyl ligands being $\pi$ acceptors will attenuate the Lewis acidity of the rhenium center and, accordingly, may have an activating effect on the complex. This could explain the relatively high activity of $\operatorname{Re}(\mathrm{CO})_{5} \mathrm{Cl}$, even though this is a $\operatorname{Re}(\mathrm{I})$ species and cannot be considered a Lewis acid.

Another factor of influence on the overall reactivity is the steric demand around the metal center, which is dependent on the number and size of the various ligands. In the case of $\mathrm{ReIO}_{2}\left(\mathrm{PPh}_{3}\right)_{2}$ and $\mathrm{ReOCl}_{3}\left(\mathrm{PPh}_{3}\right)_{2}$, the triphenylphosphine ligands might cause considerable steric hindrance around the metal center, hampering the binding of the alcohol and, thus, lowering the overall activity. Furthermore, these complexes show very different solubility characteristics, which might also play a role. Finally, the oxidation state of the complexes also may change under reaction conditions, making the exact active species unknown at this point: the low-valence rhenium complexes could be oxidized to high-valence species because the reactions are performed in air. However, we do not observe any increase in activity during the reaction when using lowvalence rhenium compounds. We also do not observe a significant color change during the reaction, and rhenium complexes in higher oxidation state are usually clearly colored. Only after prolonged reaction time color changes are observed. This indicates that any potential oxidation is a slow process compared with the rate of the dehydration reaction, thus having a minor influence on the dehydration reaction.

Because the presence of air is required for the reaction to proceed, it is possible that oxygen is involved in the reaction. Possibly the rhenium-catalyst is reduced during the catalytic cycle and requires oxidation for the catalysis to occur. For MTO, it is known that it can be reduced by $\mathrm{PPh}_{3}{ }^{22}$ sulfite, ${ }^{15}$ or $\mathrm{H}_{2}{ }^{13}$ to form a rhenium(V) species and also an alcohol can reduce the rhenium, yielding the corresponding ketone. ${ }^{23}$ However, except for the reactions with 1-octanol and borneol, performed at higher temperatures and with an alcohol difficult to dehydrate, we do not detect any traces of ketone at any point in the dehydration reaction of all other alcohols tested, rendering this pathway unlikely.

Furthermore, the presence of water could play a role; for instance, in the case of $\mathrm{Re}_{2} \mathrm{O}_{7}$, which is known to react with water to form perrhenic acid $\left(\mathrm{HReO}_{4}\right)$. The considerable difference in initial rate between these two catalysts (4.7 vs 6.3 mmol h${ }^{-1}$ ) indicates that the activity observed for $\operatorname{Re}_{2} \mathrm{O}_{7}$ at the start of the reaction can be ascribed to $\mathrm{Re}_{2} \mathrm{O}_{7}$ itself. As the reaction progresses however, the formation of $\mathrm{HReO}_{4}$ cannot be excluded as a contributing factor to the overall activity.

In conclusion, many factors are at play in determining the overall reactivity of these rhenium-based dehydration catalysts. Mechanistic studies are currently carried out on the rheniummediated dehydration reaction, which are expected to provide further insight into this matter. ${ }^{21}$

Nonbenzylic Substrate Reactivity. In the dehydration of nonbenzylic alcohols, two different trends in reactivity can be observed. When comparing the different tertiary alcohols tested (entries 2-4 in Table 1), the initial rate decreases from the allylic to the aliphatic to the homoallylic tertiary alcohol. Also when comparing the secondary alcohols tested (entry 2, table 1 and entries $1-3$, table 2 ), it is observed that the allylic secondary alcohol does react at $100{ }^{\circ} \mathrm{C}$, but the aliphatic and homoallylic secondary alcohols do not. Furthermore, the aliphatic secondary alcohol 2-octanol shows a higher conversion in a shorter reaction time than the homoallylic alcohols. Overall this leads to the following trend in substrate reactivity:

$$
\text { allylic }>\text { aliphatic }>\text { homoallylic alcohols }
$$

When comparing the various aliphatic alcohols (entry 4, Table 1 and entries 3 and 4, Table 2), it is observed that the tertiary alcohol reacts at $100{ }^{\circ} \mathrm{C}$, the secondary only at $150{ }^{\circ} \mathrm{C}$, and the primary alcohol does not show any dehydration reaction at $150{ }^{\circ} \mathrm{C}$. Also upon comparing the homoallylic alcohols (entry 3, Table 1 and entries 1 and 2, Table 2), it is observed that the tertiary homoallylic alcohol reacts at $100{ }^{\circ} \mathrm{C}$, but the secondary homoallylic alcohols only react at $150{ }^{\circ} \mathrm{C}$. This thus points to the following trend in substrate reactivity:

\section{tertiary $>$ secondary $>>$ primary alcohols}

Both these trends follow the trend in carbocation stability, indicating that a carbocation intermediate could be involved in the rhenium-catalyzed dehydration reaction. The acid-catalyzed dehydration of alcohols is known to proceed via a carbocation intermediate. $^{24,25}$ Combined with the observation that the rhenium-catalyzed and acid-catalyzed dehydration reactions show much similarity in terms of reactive substrates and formed products, it is likely that the rhenium-catalyzed dehydration reaction also proceeds via a carbocation intermediate; however, it seems that the mere involvement of a carbocation intermediate is not the only product-determining factor. Although we see mostly the same products formed with both types of catalyst (rhenium and acid), the difference in selectivity between the two in various dehydration reactions, such as the dehydration of $\alpha$-terpineol or linalool, is too large to conclude that the same mechanism is in operation. More studies are currently in progress to elucidate the mechanism of the rhenium-catalyzed dehydration reaction.

Terpene Alcohol Reactivity. When considering the results of the various tested terpene alcohols with both $\mathrm{Re}_{2} \mathrm{O}_{7}$ and $\mathrm{H}_{2} \mathrm{SO}_{4}$, it becomes clear that in most cases, $\mathrm{Re}_{2} \mathrm{O}_{7}$ shows activity similar to or higher than $\mathrm{H}_{2} \mathrm{SO}_{4}$. Of equal importance is the product selectivity, which is at least as high and in some cases much higher with $\mathrm{Re}_{2} \mathrm{O}_{7}$. With several substrates, such as $\alpha$-terpineol, carveol, and linalool, the selectivity for a single product is much higher than with $\mathrm{H}_{2} \mathrm{SO}_{4}$, whereas with substrates such as terpinen-4-ol and (iso)menthol, the selectivity is similar, but the total yield of products is significantly higher with $\mathrm{Re}_{2} \mathrm{O}_{7}$ than with $\mathrm{H}_{2} \mathrm{SO}_{4}$. The very high selectivity of $\mathrm{Re}_{2} \mathrm{O}_{7}$ in the dehydration of $\alpha$-terpineol can be attributed to the 6-fold lower rate of isomerization of the primary products limonene and terpinolene in comparison with $\mathrm{H}_{2} \mathrm{SO}_{4}$, whereas the rate of the dehydration reaction is comparable for both catalysts.

In the reactivity of the tested terpene alcohols, an interesting difference is observed between isoborneol and its isomer borneol. The former is dehydrated at $100{ }^{\circ} \mathrm{C}$, and the latter needs $150{ }^{\circ} \mathrm{C}$ to be dehydrated to camphene. To explain this difference in reactivity, two factors can be involved. The first is the electronic nature of the $\mathrm{C}-\mathrm{O}$ bond, in which hyperconjugative interactions play a crucial role. In the case of borneol, the $\mathrm{C}-\mathrm{O}$ bond of the alcohol and the hexasubstituted $\mathrm{C}-\mathrm{C}$ bond of the bridge are antiperiplanar, thus maximizing hyperconjugative interactions between the electron-rich $\mathrm{C}-\mathrm{C} \sigma$ 
bond and the antibonding $\mathrm{C}-\mathrm{O} \sigma^{*}$ bond, thereby lowering the bond energy of the $\mathrm{C}-\mathrm{O}$ bond, as has also been shown experimentally. ${ }^{26}$ In the case of isoborneol, these bonds have a torsion angle of about $90^{\circ}$, which makes hyperconjugative interactions minimal. This electronic consideration, however, contradicts our experimental observations that isoborneol reacts at $100{ }^{\circ} \mathrm{C}$ and borneol requires a higher temperature.

The other factor of influence is steric interactions. Steric interactions in borneol are smaller than in isoborneol because of the configurational differences noted above. When assuming a Brønsted acidic E1 mechanism, protonation of the alcohol is not influenced in a significant manner by steric constraints because of the small size of a proton and also because elimination of water is not influenced significantly by sterics. This elimination can, however, release much steric strain in isoborneol, thus making this a more favorable reaction compared with the same reaction in borneol. This consideration does agree with our experimental results. Depending on the exact mechanism, another factor based on steric interactions can also be of influence. An $\mathrm{S}_{\mathrm{N}}$ 2-type reaction mechanism may be operative in this reaction. In this mechanism, a protonated alcohol group is substituted to a perrhenate ester. In this case, a backside attack on the $\alpha$-carbon takes place, which is much more hindered in borneol compared with isoborneol. This consideration would also explain the distinctly different reactivity of these two substrates.

Solid Acid Catalyst Activity. To benchmark the catalytic performance of $\mathrm{Re}_{2} \mathrm{O}_{7}$ against the performance of solid acids, the activity of a series of known solid acid catalysts was tested in the dehydration of $\alpha$-terpineol. The low reactivity of the acidic sulfonated resins in this reaction is rather surprising, given the fact that para-toluenesulfonic acid, which can be considered the homogeneous analogue of these resins, was previously found to be active in the dehydration of benzylic alcohols. ${ }^{15}$ The amount of acidic sites present in these resins cannot explain their lack of activity either, since a total amount of $0.02 \mathrm{mmol}$ of acid sites is present, on the basis of the dry weight exchange capacity of the resins, which is the same as the amount of rhenium atoms present in the rhenium-catalyzed reactions. A possible explanation could be found in the characteristics of the used acid resins. Since these are hydrophilic gel resins, they could collapse in hydrophobic solvents, such as toluene. This would render the acid sites unreachable and thus destroy the activity of the resins.

In the case of the tested zeolites, mass-transfer limitations seem to be of major importance under the mild conditions used for the dehydration reaction. ZSM-5 has the smallest pore size of the three tested zeolites and shows almost no activity. The low activity that is observed could be attributed to extraframework acid sites. Zeolite Beta has much bigger pores and shows a much higher activity, while zeolite $\mathrm{Y}$ has the highest pore size and the highest activity of the three zeolites materials tested here. It is thus clear that activity is correlated with the pore size of the zeolite, indicating diffusion limitations of the substrate into the pores of the zeolites.

When considering the mesoporous material Al-MCM-41, the low activity cannot be attributed to its pore size, since it is an order of magnitude higher than that of the tested zeolites. The low activity could be attributed to its amorphous nature, which can cause a nonhomogeneous distribution of alumina in the framework and, consequently, a lower Brønsted acidity of the active sites.
The surprising inactivity of $\gamma$-alumina may be explained along a similar vein, in terms of insufficient Lewis acidity. Because the observed activity of the most active rhenium catalysts $\left(\operatorname{Re}_{2} \mathrm{O}_{7}\right.$, $\left.\mathrm{HReO}_{4}, \mathrm{ReIO}_{2}\left(\mathrm{PPh}_{3}\right)_{2}\right)$ could be attributed to their Lewis acidity (vide supra), the Lewis acidity of $\gamma$-alumina is likely of insufficient strength to catalyze the dehydration reaction under the given conditions.

Despite the fact that different solid acids with different structural factors and $\mathrm{Si} / \mathrm{Al}$ ratios were tested, making direct comparison in terms of activity difficult, it is clear from these data that $\mathrm{Re}_{2} \mathrm{O}_{7}$ shows a higher activity on a weight-basis than any of the tested solid acids. From a selectivity viewpoint, the comparison is much more straightforward, showing the superior characteristics of $\mathrm{Re}_{2} \mathrm{O}_{7}$ in this reaction, yielding only limonene and terpinolene, whereas the solid acids yield a mixture of five products and a much lower total conversion and yield.

Recycling. During the seven recycling runs carried out for $\mathrm{Re}_{2} \mathrm{O}_{7}$, a loss of activity in the dehydration reaction of $\alpha$ terpineol was observed. This loss of activity upon recycling can be attributed to two factors: first of all, the method of recycling is prone to catalyst loss during decantation considering the small amounts of catalyst used in this reaction. The other factor is the (partial) solubility of $\operatorname{Re}_{2} \mathrm{O}_{7}$ in the reaction medium, either as dissolved $\mathrm{Re}_{2} \mathrm{O}_{7}$ or, because of reaction with water, as $\mathrm{HReO}_{4}$. The loss of activity after the first recycling is $31 \%$, which is very comparable to the remaining activity of the filtrate after filtration in a separate experiment (27\%), indicating that the partial solubility of $\mathrm{Re}_{2} \mathrm{O}_{7}$ is likely to be the major factor concerning the loss of activity during recycling.

\section{CONCLUSIONS}

We have reported on a series of rhenium-based catalyst systems that are able to dehydrate various alcohols to the corresponding olefins in a very efficient manner, with $\operatorname{Re}_{2} \mathrm{O}_{7}$ as the best performing catalyst. It was found that allylic, aliphatic, and homoallylic alcohols are readily dehydrated with $\mathrm{Re}_{2} \mathrm{O}_{7}$ under relatively mild conditions, using technical grade solvents and low reaction temperatures $\left(100-150{ }^{\circ} \mathrm{C}\right)$. These conditions can also be applied to the dehydration of various terpene alcohols to yield the corresponding terpenes. As a proof of principle for its use in catalytic upgrading of essential oils, we have shown that this system is very effective in the upgrading of tea tree oil.

Comparison of $\mathrm{Re}_{2} \mathrm{O}_{7}$ with both sulfuric acid and several solid acids has shown that $\operatorname{Re}_{2} \mathrm{O}_{7}$ is the superior catalyst on the basis of both activity and selectivity. Furthermore, $\mathrm{Re}_{2} \mathrm{O}_{7}$ remains active in the dehydration of $\alpha$-terpineol during seven runs of recycling. These combined results make $\mathrm{Re}_{2} \mathrm{O}_{7}$ a highly potent catalyst for the dehydration reaction and an interesting alternative for currently used acid catalysts. Ongoing experiments in our laboratory focus on the understanding of the mechanism of operation of $\operatorname{Re}_{2} \mathrm{O}_{7}$ and other rhenium-based catalysts in alcohol dehydration reactions and on further improving the activity and selectivity of these catalysts.

\section{EXPERIMENTAL SECTION}

General: All organic compounds were obtained from SigmaAldrich and used without further purification. $\mathrm{ReIO}_{2}\left(\mathrm{PPh}_{3}\right)_{2}$ and $\mathrm{NBu}_{4} \mathrm{ReO}_{4}$ were obtained from ABCR; Re metal, $\mathrm{Re}(\mathrm{CO})_{5} \mathrm{Cl}, \mathrm{ReOCl}_{3}\left(\mathrm{PPh}_{3}\right)_{2}, \mathrm{MTO}, \mathrm{Re}_{2} \mathrm{O}_{7}, \mathrm{KReO}_{4}$, $\mathrm{NH}_{4} \mathrm{ReO}_{4}$, Montmorillonite K10, Amberlite IR120 (hydrogen 
form, 16 - 50 mesh), and Al-MCM-41 (mesostructured aluminosilicate) were obtained from Sigma-Aldrich; $\mathrm{Re}_{2}(\mathrm{CO})_{10}, \mathrm{HReO}_{4}$ (76.5\% solution in water), and Dowex 50WX8 (50-100 mesh) were obtained from Acros; and sulfuric acid (95-97\%) was obtained from Merck, and all were used without further purification. $\gamma$-Alumina $\left(250 \mathrm{~m}^{2} / \mathrm{g}, 500\right.$ $\mu \mathrm{m}<d<850 \mu \mathrm{m})$ was obtained from Engelhard. Zeolites $\mathrm{H}-\mathrm{Y}$ (CBV 720) and H-Beta (CP811E-75) were obtained from Zeolyst. H-ZSM-5 was produced by calcination $\left(500{ }^{\circ} \mathrm{C}\right.$ for $3 \mathrm{~h}$ in air) of $\mathrm{NH}_{4}$-ZSM-5 (CBV 3024E), which was also obtained from Zeolyst. Technical toluene was obtained from Interchema and used without further purification. All reactions were performed in air.

GC analysis was performed on a Perkin-Elmer Autosystem $\mathrm{XL}$ gas chromatograph equipped with an Elite-17 column (30 $\mathrm{m} \times 0.32 \mathrm{~mm} \times 0.50 \mu \mathrm{m}$ ) and a flame ionization detector. Two temperature programs were used. For the nonbenzylic alcohol dehydration, the temperature was increased from 40 to $70{ }^{\circ} \mathrm{C}$ at $5{ }^{\circ} \mathrm{C} \mathrm{min}{ }^{-1}$ and subsequently to $250{ }^{\circ} \mathrm{C}$ at $30{ }^{\circ} \mathrm{C} \mathrm{min}^{-1}$, maintaining that temperature for $5 \mathrm{~min}$. For the terpene alcohol dehydration, the temperature was increased from 100 to $250^{\circ} \mathrm{C}$ at $10{ }^{\circ} \mathrm{C} \mathrm{min}^{-1}$. GC/MS analysis was performed on a PerkinElmer Autosystem XL with Turbomass Mass Spectrometry Upgrade and a J\&W Scientific DB-17 column $(30 \mathrm{~m} \times 0.32$ $\mathrm{mm} \times 0.25 \mu \mathrm{m})$. Products were analyzed by comparison with genuine samples in GC and GC/MS. ${ }^{1} \mathrm{H}$ NMR spectra were recorded at $298 \mathrm{~K}$ on a Varian Oxford AS400 spectrometer at $400 \mathrm{MHz}$ in toluene- $d_{8}$.

Typical procedure for the dehydration of alcohols to olefins: To the catalyst was added a solution of substrate $(2 \mathrm{mmol})$ and pentadecane as internal standard $(250 \mu \mathrm{L}, 192.3 \mathrm{mg})$ in toluene $(10 \mathrm{~mL})$. The reaction flask was sealed with a septum, placed in a preheated aluminum block heater at $100{ }^{\circ} \mathrm{C}$, and magnetically stirred. Samples for GC analysis were taken by syringe, filtered over Florisil, and eluded with ethyl acetate. For the reactions analyzed by NMR, toluene- $d_{8}$ was used as the solvent, and the yield was determined against 1,3,5-trimethoxybenzene ( 0.67 mmol, $112.1 \mathrm{mg}$ ) as internal standard. When using a liquid catalyst, the same procedure was used, but the catalyst was added to the solution by Finnpipette. For the reactions at 150 ${ }^{\circ} \mathrm{C}$, the same procedure was used, but in an $18 \mathrm{~mL}$ Ace pressure tube (Sigma-Aldrich).

\section{AUTHOR INFORMATION}

\section{Corresponding Author}

*E-mail: r.j.m.kleingebbink@uu.nl.

\section{Notes}

The authors declare no competing financial interest.

\section{ACKNOWLEDGMENTS}

This research has been performed within the framework of the CatchBio program. The authors gratefully acknowledge the support of the Smart Mix Program of The Netherlands Ministry of Economic Affairs, Agriculture and Innovation and The Netherlands Ministry of Education, Culture and Science.

\section{REFERENCES}

(1) Vennestrom, P. N. R; Osmundsen, C. M.; Christensen, C. H.; Taarning, E. Angew. Chem., Int. Ed. 2011, 50, 10502.

(2) Perlack, R. D.; Wright, L. L.; Turhollow, A. F.; Graham, R. L.; Stokes, B. J.; Erbach, D. C. Biomass as Feedstock for a Bioenergy and Bioproducts Industry: The Technical Feasibility of a Billion-Ton Annual
Supply; U.S. Department of Energy and U.S. Department of Agriculture: Washington DC, 2005.

(3) Ragauskas, A. J.; Williams, C. K.; Davison, B. H.; Britovsek, G.; Cairney, J.; Eckert, C. A.; Frederik, W. J., Jr; Hallett, J. P.; Leak, D. J.; Liotta, C. L.; Mielenz, J. R.; Murphy, R.; Templer, R.; Tschaplinski, T. Science 2006, 311, 484.

(4) Werpy, T.; Peterson, G. Top Value Added Chemicals from Biomass: Vol. 1 - Results of Screening for Potential Candidates from Sugars and Synthesis Gas: U.S. Department of Energy: Washington DC, 2004.

(5) Corma, A.; Iborra, S.; Velty, A. Chem. Rev. 2007, 107, 2411.

(6) Lee, M.-H.; Lee, S.-W.; Jeon, Y.-M.; Park, D.-Y.; Ryu, J.-Y. LG Chemical Ltd.; Novel method for preparing styrenic olefins; World Patent WO2005035468, April 21, 2005.

(7) Moser, W. R.; Thompson, R. W.; Chiang, C.-C.; Tong, H. J. Catal. 1989, 117, 19.

(8) Dirkzwager, H.; van Zwienen, M. Shell International Research; Process for the preparation of styrenes; World Patent WO9958480, November 18, 1999.

(9) Larsen, G.; Lotero, E.; Petkovic, L. M.; Shobe, D. S. J. Catal. 1997, 169, 67.

(10) Lee, M. H.; Choi, E. T.; Kim, D.; Lee, Y. M.; Park, Y. S. Eur. J. Org. Chem. 2008, 5630.

(11) Schlaf, M.; Ghosh, P.; Fagan, P. J.; Hauptman, E.; Bullock, R. M. Angew. Chem., Int. Ed. 2001, 40, 3887.

(12) Zhu, Z.; Espenson, J. H. J. Org. Chem. 1996, 61, 324

(13) Ziegler, J.; Zdilla, M.; Evans, A.; Abu-Omar, M. Inorg. Chem. 2009, 48, 9998.

(14) Ahmad, I.; Chapman, G.; Nicholas, K. M. Organometallics 2011, 30, 2810.

(15) Vkuturi, S.; Chapman, G.; Ahmad, I.; Nicholas, K. Inorg. Chem. 2010, 49, 4744.

(16) Cook, G. K.; Andrews, M. A. J. Am. Chem. Soc. 1996, 118, 9448.

(17) Korstanje, T. J.; Jastrzebski, J. T. B. H.; Klein Gebbink, R. J. M. ChemSusChem 2010, 3, 695.

(18) Jacob, J.; Espenson, J. H.; Jensen, J. H.; Gordon, M. S. Organometallics 1998, 17, 1835.

(19) van Leeuwen, P.; Clement, N.; Tschan, M. Coord. Chem. Rev. 2011, 255, 1499.

(20) Yuan, Y.; Shido, T.; Iwasawa, Y. Chem. Commun. 2000, 1421.

(21) Meerwein, H. Justus Liebigs Ann. Chem. 1914, 405, 129.

(22) Herrmann, W.; Kuchler, J.; Felixberger, J.; Herdtweck, E.; Wagner, W. Angew. Chem., Int. Ed. 1988, 27, 394.

(23) Arceo, E.; Ellman, J.; Bergman, R. J. Am. Chem. Soc. 2010, 132, 11408.

(24) Macht, J.; Janik, M.; Neurock, M.; Iglesia, E. J. Am. Chem. Soc. 2008, 130, 10369.

(25) Janik, M.; Macht, J.; Iglesia, E.; Neurock, M. J. Phys. Chem. C 2009, 113, 1872.

(26) dos Santos, F. P.; Tormena, C. F.; Contreras, R. H.; Rittner, R.; Magalhães, A. Magn. Reson. Chem. 2008, 46, 107. 